\title{
COnE).(OES
}

CIÊNCIA E TECNOLOGIA

\section{EMISSÃO DE FUMAÇA PRETA POR VEÍCULOS DA FROTA DE FORNECEDORES PRESTADORES DE SERVIÇO DE UMA EMPRESA DE GRANDE PORTE E SEUS IMPACTOS NA QUALIDADE DO AR}

\author{
RAul Ribeiro Portela ${ }^{1}$, Raissa BARroso Bisol ${ }^{2}$, IZABElle Rocha FARias ${ }^{3}$ \\ ${ }^{1}$ Instituto Federal de Educação, Ciência e Tecnologia do Ceará - IFCE \\ ${ }^{2}$ Centro Universitário Estácio do Ceará \\ ${ }^{3}$ Universidade Federal do Ceará - UFC \\ <raulportela1409@hotmail.com><raissabisol@beachpark.com.br><izabellefarias27@hotmail.com> \\ DOI: <https://doi.org/10.21439/conexoes.v14i2.1372>
}

\begin{abstract}
Resumo. Existem diversos fatores que agravam os problemas da saúde pública e que impactam negativamente no meio ambiente, dentre eles a fumaça preta oriunda da queima de combustível de veículos automotores. O presente trabalho avaliou as condições de uso, manutenção e emissão da fumaça preta por veículos movidos a diesel que executam o serviço de fornecimento de uma empresa de grande porte. Para tanto, foi realizado um estudo de caso para caracterização dos veículos que compõem a frota e, posteriosmente, a realização de um diagnóstico acerca do monitoramento da emissão de fumaça preta com utilização da escala Ringelmann. Com base nos resultados, foi possível concluir a importância da implementação do diagnóstico dos veículos e da realização do monitoramento da fumaça preta, afim de mensurar possíveis alterações na qualidade do ar e seus impactos ao meio ambiente.to, um fator responsável por parcela significativa da evasão e retenção discente.
\end{abstract}

Palavras-chaves: Fumaça Preta. Qualidade do Ar. Saúde Pública. Meio Ambiente.

Abstract. They have been a health health problem and impact negative means in the environment, is always had the health of the automotive vehicles. The work carried out as a maintenance service, and the issuance of negative actions by diesel-powered vehicles that perform the supply service of a large company. For the, the study in the study of characterized the physical effects of the physical component in the black report, with the evaluation of the diagnosis of magnetic report with the application of magnetic ringmark. Based on the results, it was possible to install the vehicle diagnostics and the date of the black reduction task, the quality of sending changes in air quality and their impact on the environment.

Keywords: Black smoke. Air quality. Public health. Environment.

\section{INTRODUÇÃO}

Nas duas últimas décadas, diversos estudos epidemiológicos vem apresentando como enfoque os impactos negativos, tanto a curto como a longo prazo, que acometem a saúde pública por meio da exposição a poluição atmosférica, como o aumento da mortalidade, doenças cardiovasculares e doenças respiratórias (ARBEX et al., 2012). Dessa forma, dentre as partículas e os componentes químicos estudados como responsáveis por tais efeitos adversos, destacam-se como principais o Material Particulado (MP), Monóxido de Carbono (CO) e o gás Ozônio $\left(\mathrm{O}_{3}\right)$, pois estão envolvidos na redução significativa da expectativa média de vida (BRAGA et al., 2001).

Em uma atmosfera urbana, os poluentes classificam-se em dois grandes grupos: os poluentes provenientes de fontes primárias e os poluentes provenientes de fontes secundárias (LOUREIRO, 2005). Os poluentes primários são assim reconhecidos 
quando oriundos diretamente das fontes emissoras, porém quando estes são produtos de reações químicas e fotoquímicas passam a ser reconhecidos como poluentes secundários. (TUNDO; ZECCHINI, 2007). Tais compostos químicos podem permanecer dispersos na atmosfera por tempo indeterminado e assim apresentar efeitos variáveis ao longo do tempo e espaço.

De acordo com especialistas em mobilidade urbana, os países desenvolvidos ou em desenvolvimento sofrem com os malefícios da poluição atmosférica, cuja a principal fonte são os veículos automotivos, que agravam os problemas da saúde pública e impactam negativamente no meio ambiente. A queima de combustíveis fósseis ocasiona a emissão de gases, vapores, fuligem e enxofre, que são fortemente prejudiciais ao organismo (DRUMM et al., 2014).

As emissões geradas pelos veículos, em especial a fumaça preta, apresentam diversos elementos contaminantes como, por exemplo: monóxido de carbono (CO), hidrocarbonetos ( $\mathrm{HC})$, óxidos de enxofre $\left(\mathrm{SO}_{\mathrm{x}}\right)$, óxidos de nitrogênio $\left(\mathrm{NO}_{\mathrm{X}}\right)$ e uma grande proporção de Material Particulado (MP), uma classe de poluente constituída de poeiras, fumaças e todo o tipo de material sólido e líquido que, devido ao pequeno tamanho, mantém-se suspenso na atmosfera (JASINSKI; PEREIRA; BRAGA, 2011; YANAGI; ASSUNÇÃO; BARROZO, 2012).

Segundo Associação Brasileira de Normas Técnicas (ABNT) (NBR 6065/86), que prescreve o método de ensaio com a Escala de Ringelmann para determinar o grau de enegrecimento da fumaça do escapamento emitida por veículos movidos à diesel sob condições de aceleração livre, este seria um grande indicador de que existem problemas relacionados ao funcionamento do motor e que, consequentemente, seria um potencial gerador e emissor de poluentes para a atmosfera. Diante dessas evidências, a Escala de Ringelmann foi adotada como uma forma oficial, prevista em lei, para avaliar o funcionamento dos motores alimentados a diesel, dando o devido alerta para que os condutores façam as manutenções necessárias asssegurando o atendimento à Legislação Ambiental e às normas técnicas pertinentes (COSTA; PEREIRA, 2017).

Sabendo que os veículos representam uma das principais fontes geradoras de poluentes e que ainda existem poucos estudos relacionando à influência dessas emissões com meio ambiente. O presente trabalho realizou, por meio do estudo de caso, o diagnóstico da frota de veículos de fornecedores para o abastecimento de um complexo empresarial de turismo, afim de inspecionar os níveis de emissões de fumaça preta lançadas e promover a preservação dos recursos naturais por meio da orientação à manutenção dos veículos afim de atender às normas técnicas da Legislação Ambiental.

\section{METODOLOGIA OU MATERIAIS E MÉTO- DOS}

\subsection{Local, tipo de estudo e abordagem metodoló- gica}

A área de estudo localiza-se na cidade de Aquiraz Ceará, sendo reconhecido como um dos maiores complexos empresariais de turismo da região. O presente trabalho trata-se de um estudo de caso desenvolvido por meio de levantamento de dados exploratórios, monitoramentos e informações relevantes, quanti-qualitativas dos veículos, fornecidas pelos condutores prestadores de serviço.

\subsection{Identificação e caracterização da frota de veí- culos conduzida por fornecedores prestadores de serviço.}

Para identificação e caracterização da frota de veículos conduzida pelos fornecedores prestadores de serviço, foram coletados dados referentes à marca, modelo e ano de fabricação dos veículos, bem como o tipo de sistema de alimentação de combustível e porte (tamanho). Os dados foram coletados e organizados separadamente para cada fornecedor de serviço.

O serviço de fornecimento ao parque ocorre mensalmente, sendo em média cerca de 30 a 40 empresas encarregadas pela entrega de produtos. Tais empresas são responsáveis por suprir a necessidade em diversos setores, como alimentício, bebidas, material de construção, entre outros. Sendo os veículos, todos estes caminhões, abastecidos a óleo diesel, cujo porte, varia entre pequeno, médio e grande.

\subsection{Diagnóstico da frota de veículos fornecedores que atendem o complexo empresarial turístico.}

O diagnóstico das condições de funcionamento, manutenção e emissão de poluentes referentes aos veículos monitorados foi realizado com base no levantamento de informações acerca da frequência de revisões, regulagens, manutenções e consumo médio de combustível por veículo.

A emissão de fumaça preta foi inspecionada pela avaliação comparativa dos padrões colorimétricos da Escala Ringelmann e a cor da fumaça emitida pelos veículos. A Escala de Ringelmann é uma escala gráfica que avalia colorimetricamente a densidade da fumaça emitida por veículos movidos a diesel e é constituída 
de cinco padrões com variações uniformes de tonalidade entre o branco e o preto. De acordo com a Companhia Ambiental do Estado de São Paulo (CETESB), quanto mais escuro for coloração da fumaça, maior será o número de poluentes emitidos e maior será o grau de efeitos adversos a saúde humana. Os padrões de monitoramento são apresentados por meio de orifícios, numerados de 0 a 5 . A recomendação é que as emissões não ultrapassem o padrão $\mathrm{n}^{\circ} 2$, dessa maneira é possível controlar a coloração da fumaça emissora de poluentes que sai dos veículos e se necessário providenciar a manutenção dos mesmos (SOUZA; SILVA; JUSTINA, 2016).

As medições foram realizadas estando o pesquisador a uma distância de no mínimo 20 metros e no máximo 50 metros do tubo de escapamento do veículo monitorado, além de se posicionar de forma a não olhar em direção ao Sol. O pesquisador segurou a escala de Ringelmann com o braço esticado, e avaliou o grau de enegrecimento da fumaça de escapamento no ponto de medida, através do orifício da escala, contra o fundo preferencialmente branco. De acordo com as normas, foi estabelecido que o grau de enegrecimento da fumaça dos veículos monitorados não poderia exceder o padrão $\mathrm{n}^{\mathrm{o}} 2$ por mais de 5 (cinco) segundos consecutivos.

As inspeções foram realizadas durante o mês de junho de 2017, no período da manhã e da tarde, sempre no mesmo local.

\section{RESULTADOS E DISCUSSÃO}

Baseado nas informações fornecidas pelos responsáveis dos veículos de compõem a frota de fornecimento em estudo e nos dados obtidos por meio da inspeção da fumaça preta realizada com a escala de Ringelmann, foi possível avaliar o índice de poluição gerada por veículos movidos a diesel.

Conforme a Tabela 1 , todos os 40 veículos inclusos no estudo foram classificados de acordo com a concessionárias a que pertence os automóveis, sendo concessionária 1 com $15 / 40(37,5 \%)$ veículos, a concessionária 2 com 10/40 (25\%) veículos, da concessionária 3 com 9/40 (22,5\%) veículos, e as concessionárias 4,5 e 6 com 2/40 (5\%) veículos, respectivamente.

Ainda de acordo com a Tabela 1, a média de idade da frota entre as empresas variam de 9,5 a 4,25 anos, sendo os veículos da concessionária 2 a que apresentou a frota com veículos mais antigos em relação aos veículos da concessionária 4 , cujo os veículos apresentaram média de idade de apenas 4,25 anos.

Com relação ao porte (tamanho), ver na Tabela 2 , dentre os 40 carros que compõem a frota de automóveis
Tabela 1: Dados relacionados à caracterização dos veículos.

\begin{tabular}{ccc}
\hline Marcas dos veículos & Quantidade & $\begin{array}{c}\text { Idade } \\
\text { (média/anos) }\end{array}$ \\
\hline Concessionária 1 & 15 & 6,13 \\
Concessionária 2 & 10 & 9,5 \\
Concessionária 3 & 9 & 4,25 \\
Concessionária 4 & 2 & 6 \\
Concessionária 5 & 2 & 6,5 \\
Concessionária 6 & 2 & 8 \\
\hline
\end{tabular}

Fonte: Autor (2017).

em estudo, $11 / 40(27,5 \%)$ carros apresentaram pequeno porte, $13 / 40(32,5 \%)$ carros apresentaram médio porte e $16 / 40(40 \%)$ carros apresentaram grande porte. Sendo maioria dentre as empresas fornecedoras os veículos de grande porte.

De acordo com o sistema de alimentação do combustível, toda a frota responsável pelo fornecimento dos produtos possui o sistema de alimentação por meio de injeção eletrônica.

O Programa de Controle da Poluição do Ar por Veículos Automotores (PROCONVE), estabelecido e regulamentado desde 1986 pelo Conselho Nacional do Meio Ambiente - CONAMA e suportado pela Lei $\mathrm{n}^{\circ}$ $8.723 / 93$, estabelece que, a partir de 2006 todos os modelos de veículos movidos a diesel, produzidos no Brasil, devem estar equipados com sistema de alimentação do tipo injeção eletrônica, pois só com esse dispositivo é possível atender aos limites de emissão de poluentes. No presente estudo de caso, observamos que todos os carros inspecionados atendem a determinação da lei, pois são fabricados com sistema de injeção eletrônica, verifica-se assim a preocupação das iniciativas privadas na preservação dos recursos naturais.

Dispondo do fato de que o nível de poluentes provocados pela emissão da fumaça oriunda dos motores movidos a diesel é bem mais prejudicial em relação aos demais tipos de combustíveis, a Portaria IBAMA no 85/96 de 17/10/1996, nos remete a criação e adoção de um programa interno de autofiscalização da correta manutenção dos veículos em todas as empresas que possuírem frota própria, e considera que, a correta manutenção dos veículos é importante para permitir o controle de poluentes e auxiliar em programas de inspeção e manutenção de veículos em uso, minimizando os efeitos da poluição por fumaça preta, que dessa maneira contribuem para a degradação do meio ambiente, alterando a qualidade do ar e causando problemas relacionados a saúde.

Em relação à avaliação da fumaça preta como des- 
Tabela 2: Dados relacionados à caracterização dos veículos.

\begin{tabular}{c|ccccc}
\hline Marcas dos veículos & Pequeno & $\begin{array}{c}\text { Porte } \\
\text { Médio }\end{array}$ & Grande & Alimentação \\
\hline Concessionária 1 & 0 & 8 & 7 & Injeção eletrônica \\
Concessionária 2 & 0 & 3 & 7 & Injeção eletrônica \\
Concessionária 3 & 9 & 0 & 0 & Injeção eletrônica \\
Concessionária 4 & 2 & 0 & 0 & Injeção eletrônica \\
Concessionária 5 & 0 & 2 & 0 & Injeção eletrônica \\
Concessionária 6 & 0 & 0 & 2 & Injeção eletrônica \\
\hline
\end{tabular}

Fonte: Autor (2017).

crito na Tabela 3, os veículos foram monitorados por meio de inspeções periódicas realizadas com a escala Ringelmann, sendo analisado também, a frequência da manutenção desses veículos, que diretamente influenciam na queima incompleta do combustível e consequentemente na formação da fumaça preta, além de ser verificado o consumo médio de combustível por $\mathrm{Km} / \mathrm{L}$.

Baseado no consumo, a concessionária 1 que apresentou a média de $7,73 \mathrm{Km} / \mathrm{L}$ para o maior número de veículos avaliados no presente estudo, mostrou uma margem de menor consumo de $5,5 \mathrm{Km} / \mathrm{L}$ e uma margem de maior consumo de $12 \mathrm{Km} / \mathrm{L}$, tendo em sua composição apenas veículos de médio e grande porte.

Os resultados revelam que, dentre as avaliadas, a concessionária 2 juntamente com a 3, 4 e 6 apresentaram o maior índice de veículos fora dos parâmetros permitidos por lei, ou seja, acima do nível 2 da Escala Ringelmann, que representa o limite da normalidade em relação a densidade colorimétrica da fumaça preta.

Analisando a situação da frota de fornecedores como um todo, a Figura 1 mostra que, dos 40 veículos avaliados, $87,5 \%$ estão em conformidade com os limites preconizados pela legislação brasileira, no qual está porcentagem está composta pelos veículos cuja densidade colorimétrica é de $20 \%$ e $40 \%$, para prevenção de emissão de poluentes na atmosfera urbana.

Conforme a Tabela 4 , no que diz respeito ao regime de manutenções, as empresas apresentam variações nas realizações de vistorias que são necessárias para um bom funcionamento do veículo, sendo elas realizadas semanalmente (em 10\% dos veículos), mensalmente (em $67,5 \%$ dos veículos) e semestralmente (em $22,5 \%$ dos veículos).

Com base nos resultados apresentados, as frotas da concessionaria 1, 2 e 6 apresentam maior média de idade entre os veículos e a maior média em consumo de combustível em relação às outras concessionárias, o que permite classificar tais modelos como merecedores de

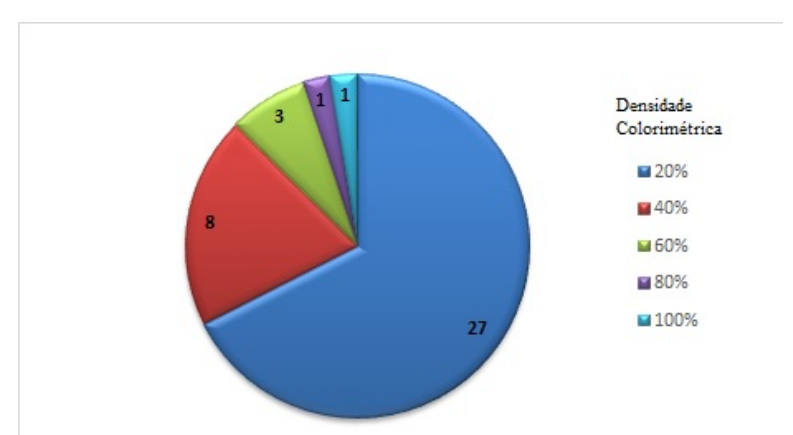

Figura 1: Gráfico de Inspeção da Fumaça Preta. Fonte: Autor (2017).

maior atenção quanto a necessidade de manutenção dos veículos. Pois devemos considerar que estas concessionárias não apresentam veículos em pequeno porte, sendo estes, bem mais econômicos que os demais.

Segundo informações obtidas pelos condutores, a rotatividade dos veículos é intensa, devido à grande demanda de entregas, fazendo com que as manutenções sejam muitas vezes esquecidas ou adiadas. Desse modo, o consumo de combustível acaba sendo maior em alguns casos, justamente pela falta de manutenção nos motores, causando consequentemente uma maior emissão da fumaça preta. Em outras palavras, a manutenção preventiva traz contribuições econômicas e ambientais, pois ao trabalharem com mais eficiência, os veículos além de consumirem menos combustível, irão emite menos poluentes.

Com relação ao diagnóstico realizado por meio da utilização da escala Ringelmann, foi possível constatar que mais da metade dos veículos apresentam níveis de emissão da fumaça preta em acordo com o IPEF - Instituto de Pesquisas e Estudos Florestais, onde estabelece, que a emissão da fumaça por veículos movidos a óleo diesel, em qualquer regime de trabalho, não poderá ex- 
Tabela 3: Dados relacionados ao diagnóstico dos veículos.

\begin{tabular}{ccccc}
\hline \multirow{2}{*}{ Marcas dos veículos } & \multicolumn{3}{|c}{ Emissão de fumaça preta } & \multirow{2}{*}{ Consumo (1//km) } \\
& Veículos avaliados & Veículos fora do parâmetro (\%) & \\
\hline Concessionária 1 & 15 & $0(0 \%)$ & 7,73 \\
Concessionária 2 & 10 & $1(10 \%)$ & 7,66 \\
Concessionária 3 & 9 & $2(22,2 \%)$ & 6,5 \\
Concessionária 4 & 2 & $1(50 \%)$ & 6,5 \\
Concessionária 5 & 2 & $0(0 \%)$ & 7 \\
Concessionária 6 & 2 & $1(50 \%)$ & 7.5 \\
\hline
\end{tabular}

Fonte: Autor (2017).

Tabela 4: Dados relacionados a frequência de manutenção dos veículos.

\begin{tabular}{c|ccc}
\hline $\begin{array}{c}\text { Marcas dos } \\
\text { veículos }\end{array}$ & \multicolumn{3}{|c}{ Manutenção } \\
Semanal & Mensal & Semestral \\
\hline Concessionária 1 & 2 & 11 & 2 \\
Concessionária 2 & 0 & 7 & 4 \\
Concessionária 3 & 1 & 6 & 1 \\
Concessionária 4 & 0 & 1 & 1 \\
Concessionária 5 & 1 & 1 & 0 \\
Concessionária 6 & 0 & 1 & 1 \\
\hline
\end{tabular}

Fonte: Autor (2017).

ceder ao padrão $\mathrm{n}^{\mathrm{o}} 2$ na Escala de Ringelmann. É valido ressaltar que mais da metade dos veículos inspecionados apresentam uma idade média jovem, ou seja, um motor mais novo, fazendo com que a emissão desses poluentes seja em um menor potencial.

\section{CONCLUSÕES}

Com base nestas considerações é de suma importância que tenhamos conhecimento sobre a qualidade do ar que respiramos, para isso é necessário identificar as fontes poluidoras e fazer o seu controle. Observamos no presente estudo que mais da metade das empresas se preocupam com a manutenção de seus veículos, fontes geradoras, mitigando dessa maneira, os impactos ao meio ambiente e as alterações na qualidade do ar.

Concluímos também no diagnóstico dos veículos a importância de que seja implementado, além de um programa de monitoramento da fumaça preta, um programa de fiscalização das condições de uso e manutenção dos veículos, afim de se ter, um maior tempo de vida útil dos motores, uma maior economia em gastos com combustível e uma menor emissão de fumaça preta ao meio ambiente.

\section{REFERÊNCIAS}

ARBEX, M. A.; SANTOS, U. d. P.; MARTINS, L. C.; SALDIVA, P. H. N.; PEREIRA, L. A. A.; BRAGA, A L. F. et al. A poluição do ar e o sistema respiratório. Jornal Brasileiro de Pneumologia, Sociedade Brasileira de Pneumologia e Tisiologia, v. 38, n. 5, p. 643-655, 2012.

BRAGA, A.; BOHM, G. M.; PEREIRA, L. A. A.; SALDIVA, P. Poluição atmosférica e saúde pública. Revista USP, v. 1, n. 51, p. 58-71, 2001.

BRASIL. Determinação $n^{\circ}$ 6065/86, de 30 de julho de 1980. determinação do grau de enegrecimento do gás de escapamento emitido por veículos. Diário Ofcial. 1980.

CETESB. Poluentes atmosféricos. 2017. Disponível em: <http://www.cetesb.sp.gov.br/Ar/ar_saude.asp>. Acesso em: 10 mai. 2017.

CONAMA. Dispõe sobre o estabelecimento de padrões nacionais de qualidade do ar determinando as concentrações de poluentes atmosféricos. 1990. Disponível em: $<$ http://www.mma.gov.br/cidades-sustentaveis/ qualidade-do-ar/padroes-de-qualidade-do-ar.html $>$. Acesso em: 22 mai. 2017.

COSTA, A. P.; PEREIRA, B. B. Emissão de fumaça preta por veículos da frota de ônibus do sistema de transporte coletivo de uberlândia e impactos na qualidade do ar. Revista GeTeC, v. 6, n. 11, p. 15-28, 2017.

DRUMM, F.; GERHARDT, A. E.; FERNANDES, G. D.; CHAGAS, P.; SUCOLOTTI, M. S.; KEMERICH, P. D. C. Poluição atmosférica proveniente de combustíveis derivados do petróleo em automotores. Eletrônica em Gestão, Educação, Tecnologia Digital. 2014. 
IBAMA. Dispõe sobre a utilização de veículo diesel para transporte de passageiros ou mercadorias. 1996. Disponível em: <https: //www.legisweb.com.br/legislacao/?id=181449>. Acesso em: 22 mai. 2017.

IPEF. Dispõe sobre o limite de emissão de fumaça por veículos movidos a óleo diesel. 1980. Disponível em: <http://www.ipef.br/legislacao/bdlegislacao/ detalhes.asp?Id=270>. Acesso em: 22 mai. 2017.

JASINSKI, R.; PEREIRA, L. A. A.; BRAGA, A. L. F. Poluição atmosférica e internações hospitalares por doenças respiratórias em crianças e adolescentes em cubatão, são paulo, brasil, entre 1997 e 2004. Cadernos de Saúde Pública, SciELO Public Health, v. 27, n. 11, p. 2242-2252, 2011.

LOUREIRO, L. N. Panorâmica sobre emissões atmosféricas:. Avaliação Do Inventário Emissões Atmosféricas da Região Metropolitana Do Rio De Janeiro/ UFRJ. 2005.

SOUZA, R. C.; SILVA, M. F.; JUSTINA, E. E. D. Emissão de fumaça preta por veículos da frota de ônibus do sistema de transporte coletivo de uberlândia e impactos na qualidade do ar. Revista Caminhos de Geografia, v. 17, n. 59, p. 279-293, 2016.

TUNDO, P.; ZECCHINI, F. Mudanças climáticas globais. A Química para o Ambiente. 2007.

YANAGI, Y.; ASSUNÇÃO, J. V. d.; BARROZO, L. V. The impact of atmospheric particulate matter on cancer incidence and mortality in the city of são paulo, brazil. Cadernos de saude publica, SciELO Public Health, v. 28, n. 1, p. 1737-1748, 2012. 